\title{
UTILIZAÇÃO DE PADRÕES DE SEDIMENTAÇÃO COSTEIRA COMO INDICADORES PALEOCLIMÁTICOS NATURAIS (PROXIES)
}

\author{
JOSÉ M.L. DOMINGUEZ* \& ABÍLIO C.S.P. BITTENCOURT*
}

\begin{abstract}
THE USE OF COASTAL SEDIMENTATION PATTERNS AS PALEOCLIMATIC INDIC ATORS OF PROXY TYPE. The feasibility of using patterns of coastal sedimentation as proxy records of climate is here demonstrated. Two examples of different sedimentation pattems, along the east-northeastern coast of Brazil are discussed in this paper: (1) patterns associated with the transport of sands along the coast by longshore drift currents, generated by waves and controlled by prevailing winds and (2) patterns of sedimentation in coastal dune fields controlled by rainfall distribution and wind pattems. In the first example, analysis of beach-ridge truncation patterns preserved in the coastal plain associated with the Doce River mouth (ES), hás shown that during the Holocene important inversions in the direcüon of the wave-generated longshore currents have occurred. These inversions are fundamentally related to changes in the pattern of atmospheric circulation, that prevented E-SE trade winds to reach this region, probably due to a latidudinal displacement of the South Atlantic ocean high pressure cell. In the second example, contrary to what is usually believed by some specialists, it is concluded that climate in the coastal zone is an important agent for the accumulation of aeolian deposits. In the dune field adjacent to the Atalaia beach (PI) the supply of sediments from the beach face, in a yearly basis, is strongly controlled by rainfall distribution. Analysis of spatial dune distribution in the dune field itself hás shown that the sediment supply in a more extended time scale hás occurred in the form of pulses, alternating with periods during which there hás been a considerable reduction of sediment supply. This fact suggests a relationship between sediment supply and changes in rainfall precipitation, in a decade scale, which might be probably related to changes in the seasonal shift of the Intertropical Convergence Zone.
\end{abstract}

Keywords: Climatic indicators, dunes, beach-ridges.

\begin{abstract}
RESUMO Este trabalho demonstra a praticabilidade de se utilizar padrões de sedimentação costeira como indicadores paleoclimáticos naturais (proxies). Dois tipos desses padrões, representativos da costa lestenordeste brasileira, são aqui discutidos: 1. padrões associados ao transporte de sedimentos arenosos ao longo da costa por correntes de deriva litorânea, geradas por ondas e controladas climaticamente pelo sistema de ventos dominante; e 2. padrões de sedimentação em campos de dunas costeiras controlados climaticamente por taxas de precipitação e padrões de vento. No primeiro caso, a partir de testemunhos registrados na planície costeira associada à desembocadura do Rio Doce (ES), foram registradas importantes inversões no sentido da deriva litorânea, que devem estar relacionadas fundamentalmente a mudanças no padrão de circulação atmosférica que tenham impedido os ventos alíseos de E-SE de alcançarem essa região, mediante deslocamentos latitudinais na célula de alta pressão do Atlântico Sul. No segundo caso, diferentemente do que consideram alguns especialistas, concluiu-se que o clima é um fator importante para a acumulação de depósitos eólicos ao longo da costa. Desse modo, no campo de dunas adjacente à praia de Atalaia (PI), ficou evidenciado que o suprimento de sedimentos para o mesmo, durante os tempos recentes, não foi um processo contínuo, tendo ocorrido na forma de pulsos, alternando-se com períodos durante os quais o suprimento foi consideravelmente reduzido, 0 que sugere estar este fato relacionado a mudanças na precipitação atmosférica, ligadas à Zona de Convergência Intertropical, aluando na escala de décadas.
\end{abstract}

Palavras-chave: Indicadores climáticos, dunas, cordões litorâneos.

INTRODUÇ̃̃O Estudos nas últimas décadas, realizados no exterior e mesmo no Brasil (Ab' Saber 1977, Bradley 19S5, Absyetal. 1993, Turcq et al. 1993), têm demonstrado amplamente que o clima não é fixo, mas variável em escalas de tempo, que vão desde milhões de anos até décadas. Mudanças climáticas na escala de tempo de séculos ou décadas podem produzir mudanças ecológicas significativas e comprometer o bem estar do homem no planeta. Assim é que, nas três décadas que precederam o ano de 1972, as nações do mundo, auxiliadas por avanços na ciência e tecnologia agrícola, mantiveram a produção de alimentos à frente de uma população rapidamente em crescimento. Entretanto, a partir de 1972, a economia internacional tem sido fortemente influenciada por eventos climáticos (Bryson \& Murray 1977), com a produção agrícola mundial sendo significativamente reduzida por secas, geadas, ou condições de tempo extremamente úmidas, com outros efeitos igualmente adversos às atividades humanas, tais como grandes enchentes.

Encontra-se muito bem documentado na literatura que o declínio de civilizações agrícolas antigas, tais como os
Harappa (índia), as comunidades indígenas de Mill Creek (grandes planícies dos Estados Unidos), a civilização Micênica, e as colónias norse na Islândia e Groenlândia, está intrinsecamente associado a mudanças climáticas ocorridas durante os últimos 5.000 anos (Bryson \& Murray 1977). Não se trata, portanto, de mero capricho académico o interesse no estudo de mudanças climáticas.

A completa compreensão da base física do clima e das variações climáticas depende de se poder examinar o sistema atmosfera-oceano-gelo sob ampla gama de diferentes condições. A maior parte das ideias de como o sistema climático funciona baseia-se em observações do clima atual. Essas ideias só serão úteis na projeção de climas futuros se puderem ser calibradas sob ampla gama de condições (US-GARP 1975). O conhecimento de variações climáticas está fundamentalmente confinado ao registro dos últimos dois séculos. Todavia, duas outras fontes de dados estão disponíveis, permitindo estender o registro do clima para períodos pré-instrumentais (US-GARP 1975): fontes históricas, que constituem os chamados dados climáticos "históricos", e vários registros climáticos naturais, que dão origem aos chamados 
dados climáticos do tipo proxy. Os melhores registros históricos são originários de apenas duas partes do mundo, China e Japão, e noroeste europeu. Registros históricos para o hemisfério sul são quase inexistentes, o que têm sido fator de preocupação nas tentativas de se descrever mudanças climáticas globais a partir desses registros (Gribbin \& Lamb 1978). Como resultado, reconstruções paleoclimáticas para o hemisfério sul, por necessidade, têm que limitar-se apenas a indicadores climáticos naturais (proxies). Nesse sentido, até o presente, o registro climático tem se baseado no uso de vários sistemas registradores naturais, tais como anéis de crescimento de árvores, sedimentos lacustres laminados, testemunhos de gelo, análise de pólen etc. Mais recentemente, estudos do Sistema Quaternário Costeiro do Brasil (Martin \& Suguio 1992, Dominguez et al 1992) sugerem ser exequível, para tal fim, a utilização de padrões de sedimentação costeira em regiões dominadas por ondas, como é o caso das costas leste e nordeste do Brasil.

O objetivo deste trabalho é, portanto, o de discutir a praticabilidade de se utilizar esses padrões de sedimentação costeira como indicadores paleoclimáticos naturais e despertar a comunidade de estudiosos do Quaternário no Brasil para avaliar e testar as hipóteses aqui levantadas.

Dois tipos de padrões de sedimentação costeira serão discutidos aqui: (1) padrões associados ao transporte de sedimentos arenosos ao longo da costa por correntes de deriva litorânea geradas por ondas, controladas climaticamente pelo sistema de ventos dominante; e (2) padrões de sedimentação em campos de dunas costeiras, controlados climaticamente por taxas de precipitação e padrões de vento.

Este trabalho está organizado da seguinte maneira: primeiro será feita uma breve explanação sobre a circulação atmosférica e os padrões de precipitação responsáveis pelo clima que caracteriza a região costeira leste e norte-nordeste do Brasil. Em seguida, serão analisados alguns experimentos de campo que vieram a demonstrar o controle climático na sedimentação costeira. Finalmente, serão discutidas as possíveis aplicações de estudos de evolução costeira na reconstrução de paleoclimas.

CIRCULAČ̃̃O ATMOSFÉRICA NA COSTA LESTENORDESTE DO BRASIL Os elementos básicos da circulação atmosférica, ao longo da costa do Brasil, incluem, segundo Bigarella (1972) (Fig. 1): (a) massas de ar originárias na célula de alta pressão do Atlântico Sul e (b) avanço semiperiódico de massas de ar de origem polar. A célula anticiclônica semi-estacionária do Atlântico Sul constitui o principal centro de circulação. Na porção norte e oeste do Atlântico Sul, a célula de Alta Pressão inicia os ventos alísios soprando em direção ao equador. Eles constituem os ventos de sudeste e de leste, que sopram ao longo de todo o ano nas costas norte e nordeste do Brasil (Fig. 2). Na porção sudoeste da célula de alta pressão, os ventos de retorno têm início e sopram ao longo da costa leste do Brasil como ventos de leste e nordeste (Fig. 2). A zona onde os ventos alísios e os ventos alísios de retorno divergem é conhecida como zona de divergência. Ao longo da costa, essa zona migra em direção ao equador no verão e em direção ao sul no inverno (Fig. 2). A zona de divergência está localizada ao redor de $10^{\circ} \mathrm{S}$, durante o mês de janeiro, e de $20^{\circ} \mathrm{S}$, durante o mês de julho (Fig. 2). Na realidade, essa zona de divergência corresponde ao limite entre a massa equatorial atlântica e a massa tropical atlântica. Ao norte da zona de divergência, ao longo da costa, os ventos sopram principalmente de sudeste e leste, enquanto ao sul desta zona os ventos sopram principalmente de nordeste e leste (Fig. 2).

A migração sazonal da zona de divergência dos ventos alísios deve-se a dois fatos: (1) deslocamento sazonal da célula de alta pressão do Atlântico, com mudanças da ordem de $5^{\circ}-10^{\circ}$, respondendo a variações de insolação do hemis-

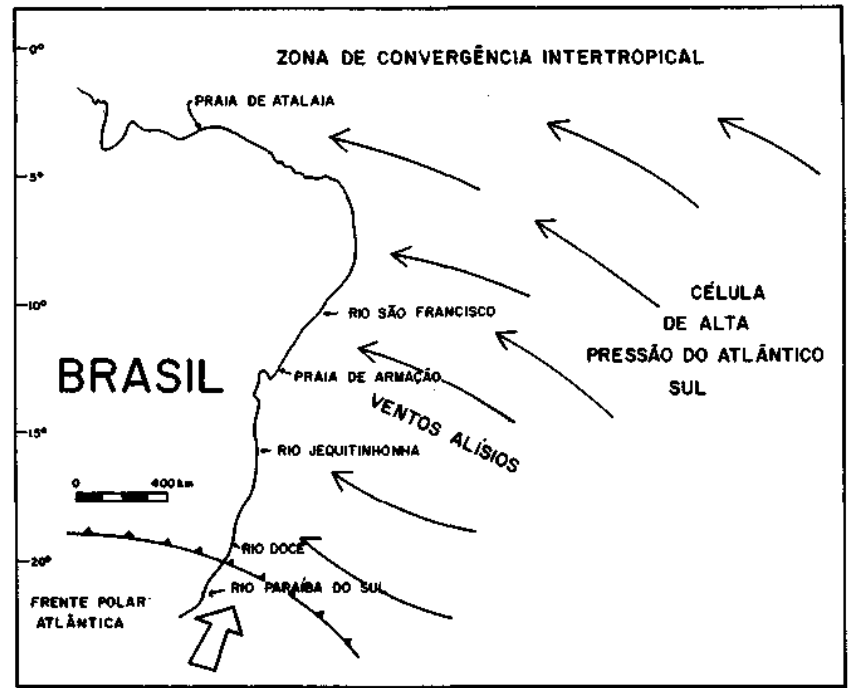

Figura l - Elementos básicos da circulação atmosférica afetando as zonas costeiras leste e nordeste do Brasil (modificado de Dominguez et al. 1992)

Figure 1 - Major elements of the atmospheric circulation affecting the east-northeastern coast of Brazil (modified from Dominguez et al. | 992)
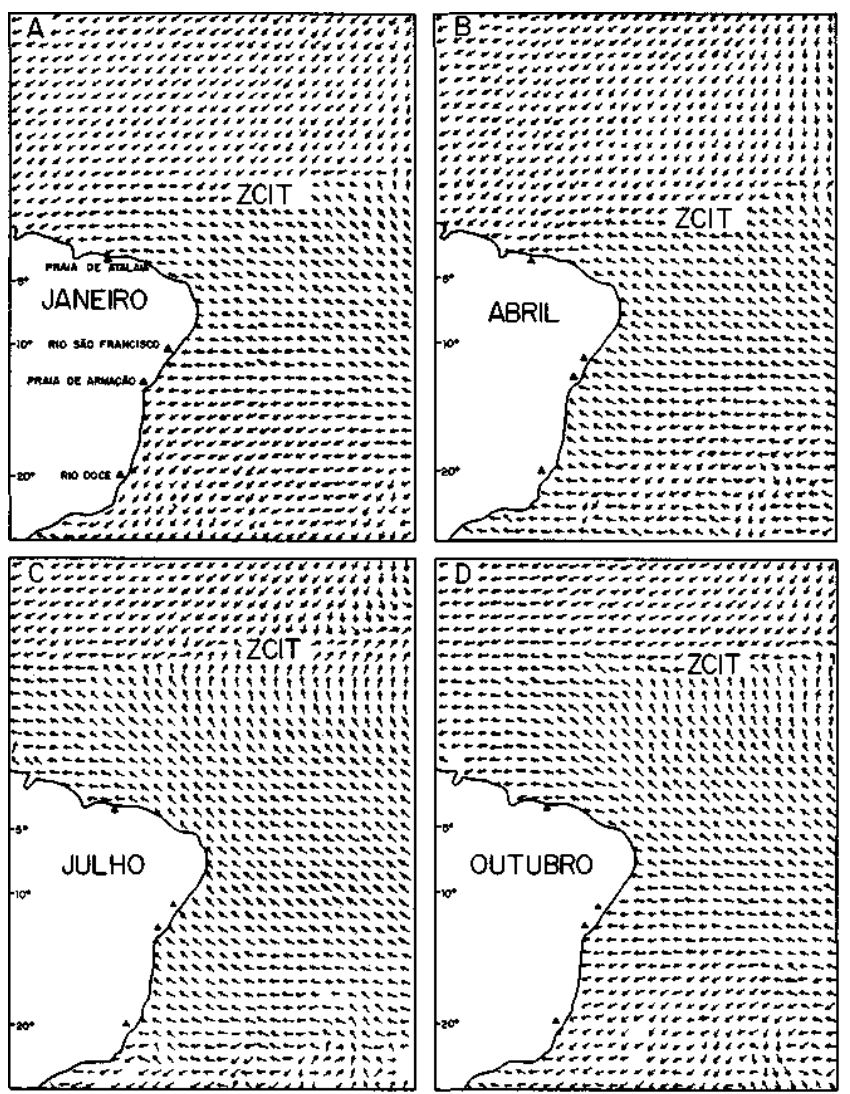

Figura 2 - Ventos resultantes para o Oceano Atlântico Sul - para os meses de janeiro, abril, julho e outubro (modificado de Hastenrath \& Lamb 1977). ZCIT = Zona de Convergência Intertropical

Figure 2- Resultant winds for part of the Atlantic Ocean, for the months of january, april, july and october (modified from Hastenrath \& Lamb 1977). ZCIT = Intertropical Convergence Zone

ferio relacionadas à sucessão de estações; e (2 ) no verão, o maior aquecimento do continente em relação ao mar resulta no aparecimento de uma depressão térmica continental, que força os ventos alísios a tangenciarem o litoral leste do Brasil (Nimer 1989). 
A Frente Polar Atlântica, originada na Antártida, invade o continente sul-americano sob a forma de grandes anticiclones, a leste da cordilheira andina. Essa frente, condicionada pelo contraste térmico (continente-oceano) e pela orografia, divide-se em dois ramos que seguem caminhos distintos: a oeste e a leste do maciço brasileiro. $\mathrm{O}$ ramo leste se desloca pelo litoral em direção ao equador, alcançando latitudes de $10^{\circ} \mathrm{S}$ durante o inverno e, raramente, alcançando o trópico no verão. $\mathrm{O}$ avanço da Frente Polar Atlântica dá origem a vigorosos ventos de sul - sudeste.

Os padrõ̃es de precipitação ao longo da região costeira leste e norte-nordeste do Brasil são controlados pelo padrão de circulação atmosférica descrito acima.

PADRÕES DE TRANSPORTE DE SEDIMENTOS AO LONGO DA COSTA POR CORRENTES DE DERIVA LITORÂNEA GERADAS POR ONDAS A dispersão de sedimentos arenosos ao longo da costa, em ambientes dominados por ondas, resulta essencialmente da atividade das ondas que, ao se aproximarem da linha de costa formando um ângulo agudo, geram uma corrente que flui paralelamente à mesma. Essa corrente, associada ao movimento em zigue-zague das partículas sedimentares (swash transport), provocado pela atividade de espraiamento das ondas de encontro à face da praia, constitui o principal agente responsável pela deriva litorânea de sedimentos ao longo da costa. Como os trens de ondas que alcançam a linha de costa são gerados pelo vento, cujos padrões são controlados essencialmente pelo clima (descontadas aí as variabilidades locais associadas a fenómenos do tipo refração e difração de ondas), mudanças na direção dos ventos devem ocasionar mudanças nos padrões de dispersão ao longo da costa.

Geração de ondas ao longo da costa leste do Brasil O potencial da energia eólica para a geração de ondas gravitacionais na superfície dos oceanos é resultado da velocidade do vento, da duração de tempo em que o vento sopra em uma determinada direção e da distância ao longo da qual o vento sopra (fetch). Embora a velocidade e ofetch sejam fatores relevantes, a variável mais importante parece ser a proporção de tempo que os ventos com uma determinada velocidade são registrados em uma localidade particular (Davies 1972). As regiões que apresentam frequências relativamente altas de ventos fortes (gale) (força 8 ou superior, na escala de Beaufort) são, segundo esse autor, por consequência, as principais regiões de geração de ondas. Essas regiões estão localizadas nos cinturões de tempestade de alta latitude, em ambos os hemisférios (Davies 1972). O fato de o cinturão de tempestade do hemisfério sul se localizar quase que inteiramente sobre o mar, associado com a ocorrência de elevada frequência de ventos fortes (gales), sua persistência relativa em localização e as longas distâncias sobre as quais eles sopram, tornam essa região a área de geração de ondas mais importante e mais claramente definida do mundo (Davies 1972). O marulho (swell) que emana dos cinturões temperados de tempestade percorre grandes distâncias. A direção que essas ondas tomam é controlada pela direção dos ventos geradores. Pelo fato de a componente oeste - leste dos gales de latitude temperada ser muito mais importante que a componente leste - oeste, o marulho no sentido de sudeste será aquele que apresentará particular importância no hemisfério sul. Isso significa que essas ondas não exercem qualquer influência significativa sobre os processos geomórficos que têm lugar ao longo das costas leste e nordeste do Brasil.

Por outro lado, se forem considerados ventos com força 4 da escala de Beaufort (velocidade mínima $5 \mathrm{~m} / \mathrm{seg}$ ) como um valor mínimo abaixo do qual ondas com significado geomórfico normal são improváveis de serem geradas (Davies 1972), é possível identificar outras regiões nas quais a produção de ondas é provável, além dos cinturões de tempestade de altas latitudes. Essas outras zonas ocorrem em ambos hemisférios em torno de $10^{\circ}$ e $20^{\circ}$ do equador, correspondendo, portanto, aos cinturões de ventos alísios. A consistência dos ventos alísios, entretanto, afeta seções relativamente pequenas das costas tropicais orientais, conforme bem observado por Davies (1972). Ainda segundo esse autor, os únicos trechos extensos de zonas costeiras continentais fortemente influenciados por ondas geradas por ventos alísios estão no Brasil e na África Oriental.

Outro importante fator influenciando a geração de ondas ao longo da costa leste do Brasil é o deslocamento da Frente Polar Atlântica. Esse deslocamento dá origem a ventos vigorosos de sul - sudeste, os quais irão gerar ondas apresentando esta direção preferencial de propagação.

Portanto, a costa leste do Brasil, até o paralelo de $10^{\circ} \mathrm{S}$, é afetada por dois padrões de ondas, um de N-NE e outro de $\mathrm{SE}$, associados aos ventos alísios originários no anticiclone do Atlântico Sul, este último reforçado pelo avanço da Frente Polar Atlântica.

\section{CORDÕES LITORÂNEOS COMO INDICADORES PALEOCL1MATICOS NATURAIS Experimento de campo - Praia de Armação (Salvador - BA)}

Um monitoramento das variações morfodinâmicas da Praia de Armação (Salvador/BA) (Fig. 3), realizado por Farias et ai. (1985) durante 19 meses consecutivos, que, continuamente, foi expandido por Bittencourrt et al. (1987) por mais 12 meses, demonstra a existência de estreito relacionamento entre os padrões de vento e o sentido da deriva litorânea gerada por ondas. A Praia de Armação apresenta cerca de 3 $\mathrm{km}$ de extensão, exibindo o formato de uma suave enseada, com os seus extremos limitados por promontórios rochosos do embasamento cristalino, que bloqueiam qualquer trânsito litorâneo de materiais entre a mesma e as praias vizinhas. Esse monitoramento mostrou que as duas extremidades da Praia de Armação exibem comportamentos opostos e alternados, com uma fase erosiva numa extremidade correspondendo a uma construtiva na outra (Fig. 4). Esses ciclos de praia não são da mesma categoria daqueles descritos por Shepard (1950) (perfis de verão e inverno). Ao invés, segundo Farias et al (1985), essas trocas de materiais de um extremo para outro da praia estão estreitamente relacionadas com a sazonalidade do regime de ventos atuante na região. Esses autores demonstraram que durante períodos nos quais dominaram ventos do octante SSE, a extremidade A (Perfil 1) (Fig. 4) experimentou erosão, enquanto uma fase deposicional caracterizou a extremidade B (Perfil 3) (Fig. 4). O oposto ocorreu quando ventos de E e ENE foram dominantes. Nenhuma mudança significativa foi observada no trecho intermediário da praia (Perfil 2, Figs. 3 e 4).
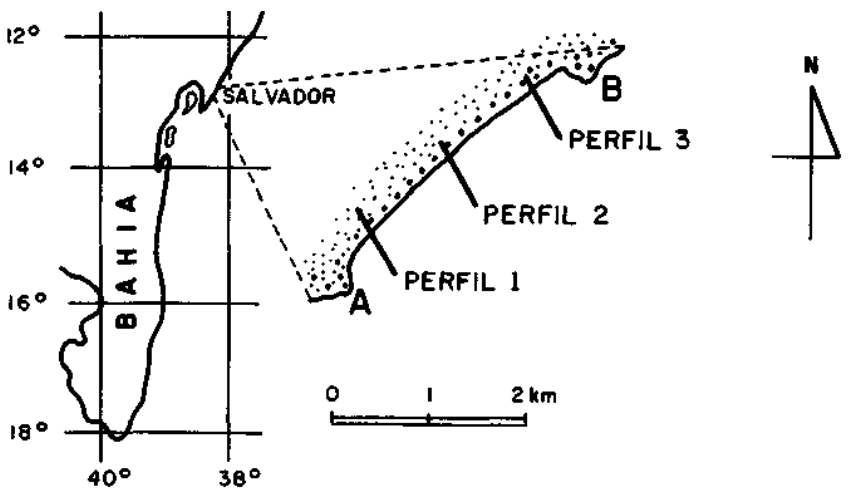

figura 3 - Praia de Armação (Salvador - BA), mostrando a localização dos Perfis 1,2 e 3 ilustrados na figura 4 Figure 3 - Armação beach (Salvador - BA). Also depicted are locations of profiles 1,2 and 3 shown in figure 4 


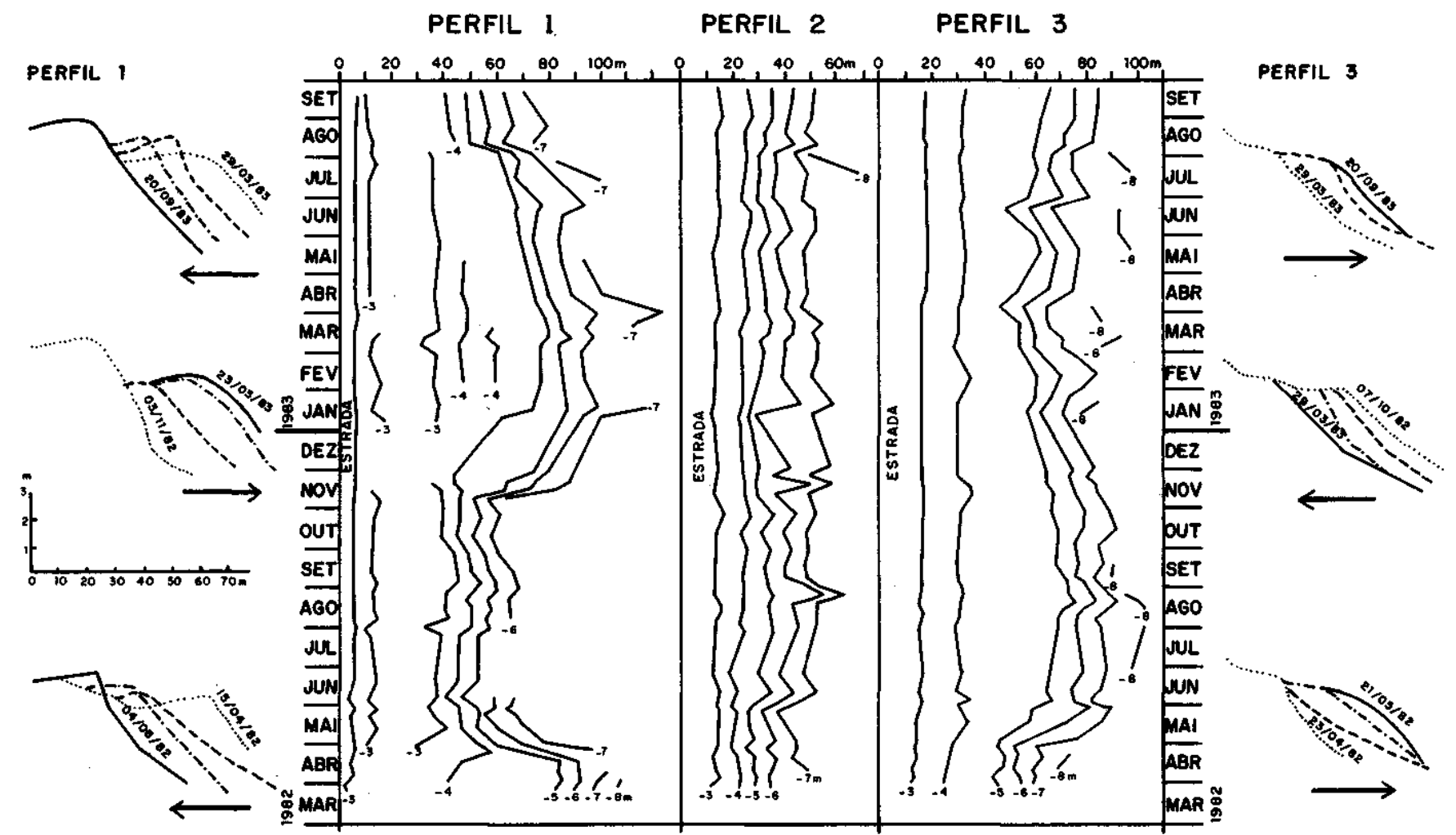

Figura 4 - Mudanças no perfil de praia para a Praia de Armação (Salvador - Bahia). Os diagramas de isolinhas na porção central da figura mostram variações na elevação da superficie da praia no decorrer do tempo, medidas a partir de um datum horizontal que intercepta o prisma de praia na região de pós-praia. Conseqüentemente, as diferenças de elevação são negativas. As isolinhas conectam pontos de igual elevação em relação a este datum. Seções transversais para o perfil 2 não são mostradas, porque as variações sazonais observadas são insignificantes nesse local. Para localização dos perfis, ver figura 3 (modificado de Farias et al. 1985)

Figure 4- Changes in beach profile through time documented for the Armação beach. Isopleth diagrams in the central part of the graph show variations in beach surface elevation through time measured from a horizontal datum that intercepts the beach prism in the backshore. Thus, diferences in elevation are negative. Isopleths connnect equal elevation points relative to this datum. Cross-sections of Profile 2 are not shown because almost no seasonal changes were observed at this location (see figure 3 for location of profiles 1, 2 and 3) (modified from Farias et al. 1985)

Por fim, durante o período do monitoramento realizado pêlos citados autores, ocorreu o fenómeno meteorológico "El Nino" do ano de 1983, que se caracterizou por dificultar sobremaneira, durante sua ocorrência, a passagem da Frente Polar Atlântica para as regiões de latitudes mais baixas, como é o caso de Salvador. Como consequência, os ventos provenientes de S, que acompanham essas frentes-frias, escassearam. Esses ventos, pelo fato de serem mais fortes, geram ondas de maior altura, as quais produzem pela deriva litorânea grande movimentação de materiais ao longo da praia no sentido da extremidade A para B (Farias et al 1985). Na ausência desses ventos de sul, as taxas de transporte associadas à deriva litorânea diminuíram nesse período e, desse modo, a erosão da extremidade A e a concomitante construção da extremidade B ocorreu apenas sob o efeito dos ventos alísios de S SE presentes no período $\mathrm{e}$, por conseguinte, foi muito lenta.

O monitoramento da Praia de Armação mostra, portanto, que os padrões de dispersão de sedimento em linhas de costa dominadas por ondas são extremamente sensíveis a mudanças na direção dos ventos e, também, o quão dependente este tranporte está em relação aos ventos alísios e ao avanço da Frente Polar Atlântica. Observe-se, ainda, que pequena mudança climática de curta duração, como o "El Nino", impedindo o avanço da frente polar, afetou de maneira acentuada a dispersão de sedimentos na zona costeira.
Planície de cordões litorâneos do Rio Doce (ES) Planícies de cordões litorâneos são compostas principalmente de depósitos de praia que exibem na sua superfície cordões litorâneos (beach ridges) bem preservados. Cada cordão litorâneo foi formado individualmente como um depósito associado à linha de costa, com o cordão litorâneo mais externo representando o cordão mais recente da série. Os cordões litorâneos constituem, portanto, linhas de crescimento da linha de costa e, quando preservados, permitem aos estudiosos decifrarem a história de desenvolvimento da mesma (Komar 1976).

Na costa leste do Brasil, ocorrem numerosas planícies de cordões litorâneos nas quais a progradaçãò da linha de costa foi favorecida por um abaixamento de cerca de $5 \mathrm{~m}$ do nível relativo do mar, durante os últimos 5.000 anos (Dominguez et al. 1987). Nessas planícies, é possivel identificar diversos sistemas de cordões litorâneos separados uns dos outros por linhas de truncamento de caráter erosivo e que podem representar: 1. pequenas elevações do nível relativo do mar;

2. mudanças na posição de desembocaduras fluviais; e 3. mudanças no sentido da deriva litorânea associadas a mudanças na direção de aproximação das ondas. A partir do uso de indicadores geomórficos, tais como a orientação dos cordões litorâneos, esporões etc., nas planícies de cordões litorâneos dos Rios Paraíba do Sul, Doce e Jequitinhonha (Fig. 1). Dominguez et al. (1983) e Dominguez (1987) con- 
cluíram que, para a costa leste do Brasil, durante os últimos 5.000 anos, a direção preferencial da deriva litorânea de sedimentos induzida pela ação das ondas tem sido persistentemente de sul para norte. Mapeamento detalhado e reconstruções paleogeográficas da planície costeira do Rio Doce (Dominguez 1987, Dominguez \& Wanless 1991) mostraram que, entre 5,1 Ka e 3,8 Ka, a porção norte dessa planície foi afetada por importantes inversões no sentido da deriva litorânea, muito possivelmente relacionadas a mudanças no regime de ondas. Essas reconstruções paleo-geográficas da planície costeira do Rio Doce mostram que, por volta de 5,1 $\mathrm{Ka}$, a cadeia de ilhas-barreira então existente, infletia abruptamente em direção ao continente, originando uma ampla enseada em sua porção norte (Fig. 5A). A tendência da face da costa (shorefacé) é manter a sua continuidade lateral, eliminando descontinuidades da linha de costa (Swift 1975). Em consequência, quando a linha de costa curva-se em direção ao continente, formando uma enseada, como foi o caso da porção norte da cadeia de ilhas-barreira representada na figura $5 \mathrm{~A}$, a dinâmica costeira irá atuar para eliminar essa descontinuidade. Esse processo ocorreu segundo mecanismo descrito a seguir. A face da costa alimentada pela deriva litorânea de sedimentos, direcionada de sul para norte, começou a progradar para dentro da enseada. Como resultado da progradação lateral, pontais arenosos se formaram e se estenderam para norte no oceano aberto, bastante afastados da linha de costa no setor côncavo (Fig. 5A). A refração das ondas de S-SE, assim como as ondas de N-NE, forçaram o pontal arenoso a migrar em direção ao continente, até sua extremidade setentrional juntar-se à linha de costa. Em vários casos, este processo deu origem a lagunas alongadas separadas do mar aberto pelo próprio pontal. Essas lagunas mais tarde se tornaram as áreas baixas alongadas que separam os conjuntos de cordões litorâneos na poção norte da planície costeira. Mudanças temporárias na circulação atmosférica causaram inversões no sentido preferencial da deriva litorânea, que então passou a ser de norte para sul (Fig. 5B). As inversões foram provavelmente breves, da ordem de décadas, mas foram suficientes para causar truncamentos na orientacão da linha de costa, como observado na porção norte da planície costeira. As reversões no sentido da deriva litorânea foram atribuídas, por Dominguez (1987) e Dominguez et al. (1992), a deslocamentos latitudinais na posição da célula de alta pressão do Atlântico Sul.

Martin \& Suguio (1992) propuseram estarem essas inversões relacionadas apenas a um bloqueio do avanço da Frente Polar Atlântica, por fenómenos do tipo "El Nino". Aqui, discorda-se dessa interpretação, e os motivos para isto são os seguintes: Embora, efetivãmente, fenómenos atmosféricos do tipo "El Nino", como demonstrado por Farias et al. (1985), consigam barrar os avanços periódicos da Frente Polar Atlântica e, conseqüentemente, os ventos de S-SE que a acompanham, geradores de uma deriva litorânea no sentido de sul para norte, não significa que, durante tal situação, uma deriva nesse sentido deixe de existir. $\mathrm{Na}$ realidade, em tais circunstâncias, significativa deriva litorânea de sul para norte ainda persiste, induzida pêlos ventos alísios de E-SE, como também demonstrado por Farias et al. (1985), na Praia de Armação, localizada, à semelhança da planície costeira associada à desembocadura do rio Doce, dentro da zona de migração da célula de alta pressão do Atlântico Sul, entre $10^{\circ}$ e $20^{\circ} \mathrm{S}$ (Fig. 2). Desse modo, as reversões no sentido da deriva litorânea registradas nessa região devem estar relacionadas fundamentalmente a mudanças no padrão da circulação atmosférica que tenham impedido os ventos alísios de E-SE de alcançarem a região, mediante deslocamentos na posição da célula de alta pressão do Atlântico Sul para norte $\mathrm{e}$, conseqüentemente, submetendo essa região apenas aos ventos alísios de E-NE, geradores de uma deriva no sentido de norte para sul.
Curray et al. (1967), estudando a planície de cordões litorâneos de Nayarit (costa oriental do México), relataram também inversões na direção da deriva litorânea induzida pelo vento para aquela região durante o Holoceno, interpretando estas inversões como causadas por mudanças no padrão dos ventos, relacionadas por sua vez a mudanças climáticas.

DUNAS COSTEIRAS COMO INDICADORES PALEOCLIMÁTICOS NATURAIS Experimento de campo - Praia de Atalaia (PI) O clima, através da precipitação, controla não-somente a migração das dunas ativas mas também o suprimento de sedimentos para os campos de dunas. Um pequeno experimento realizado na Praia de Atalaia (Fig. 6) revelou como se processa esse mecanismo (Bittencourt et al. 1990). A Praia de Atalaia está associada com um extenso campo de dunas, caracterizado por barcanas isoladas migrando no sentido de sudoeste. Essa praia é do tipo dissipativo (Wright \& Short 1982), apresentando ampla face da praia com baixa declividade, onde inexistem bermas. O clima nessa região é quente e úmido, com precipitação anual de $100-125 \mathrm{~cm}$, sendo as chuvas essencialmente controladas pela posição da Zona de Convergência Intertropical (ZCIT) (Fig. 2) (Lins 1978). A estação chuvosa ocorre no verão - outono, quando a ZCIT move-se para sul; a seca, no inverno - primavera, quando a ZCIT se dirige para distante da costa, e as chuvas cessam (Fig. 2).

O monitoramento das mudanças texturais nos sedimentos da Praia de Atalaia mostrou uma relação muito próxima entre as mesmas e a precipitação atmosférica (Bittencourt et ai 1990). O monitoramento estendeu -se por um período de 9 meses consecutivos e as amostras foram sempre coletadas nos $2 \mathrm{~cm}$ superiores da face da praia, num ponto médio entre a baixa e a preamar. Ademais, as amostras foram sempre coletadas o máximo possível próximas do horário da baixa-mar. Esses autores mostram que, durante a estação chuvosa, os valores da mediana para as areias da face da praia têm um valor de $0,150 \mathrm{~mm}$; durante a estação seca, os mesmos elevam-se para 0,700 mm (Fig. 6). A par disso, foi também constatado que as velocidades dos ventos durante a estação seca foram significativamente maiores do que na estação chuvosa (Fig. 6). Uma vez que mudanças significativas no perfil praial não foram observadas durante o período de monitoramento, Bittencourt et al (1990) interpretaram essas mudanças como resultantes de remoção seletiva de sedimentos da face da praia pela ação dos ventos. Assim, durante a estação chuvosa, as chuvas ininterruptas umedecendo os sedimentos da face da praia, juntamente com os fracos ventos existentes nessa época, inibiram a deflação dos sedimentos finos da face da praia (Fig. 6). Conseqüentemente, durante esse período, os sedimentos praiais são constituídos predominantemente de areia fina a muito fina, com valores médios em torno de $0,150 \mathrm{~mm}$. Por outro lado, durante a estação seca, ventos soprando conti-nente adentro removem uma significativa porção das frações areia fina a muito fina dos sedimentos da face da praia, alimentando, dessa forma, o campo de dunas ativas contíguo (Fig. $6)$. Desse modo, maiores valores da mediana $(0,700 \mathrm{~mm})$ caracterizam os sedimentos da face da praia durante o período.

Quanto ao campo de dunas contíguo, durante a estação chuvosa, a migração é virtualmente interrompida e as áreas interdunares são alagadas, originando pequenas lagoas que se tornam interconectadas, drenando para o mar. Durante a estação seca, a migração das dunas é retomada e as áreas interdunares secam. Como consequência, as regiões interdunares são caracterizadas pela presença de pequenas cristas arqueadas, cuja concavidade aponta no sentido de migração das dunas (Prancha 1). Essas cristas arqueadas, 


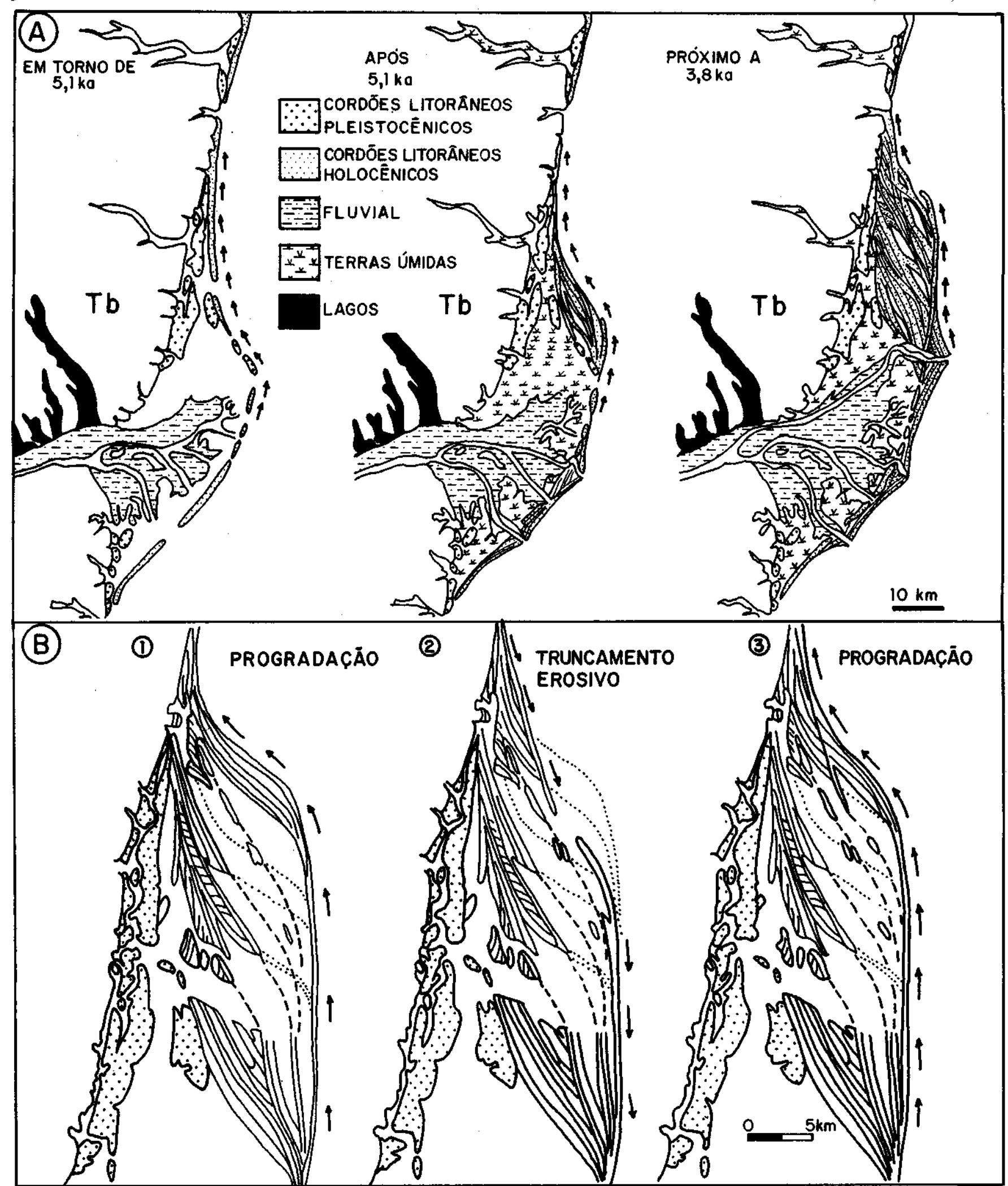

Figura 5 - Planície de cordões litorâneos do Rio Doce (ES). A. Mapas paleogeográficos da planície costeira do Rio Doce, para o periodo 5,1 Ka a 3,8 Ka (modificado de Dominguez 1987). B. Ampliação da porção norte da planície costeira do Rio Doce, ilustrando a origem dos truncamentos nos conjuntos de cordões litorâneos. Estes truncamentos resultam de inversões no sentido da deriva litorânea. As linhas pontilhadas indicam a orientação da linha de costa durante períodos de progradação. As linhas tracejadas indicam a orientação da linha de costa durante períodos de erosão, associados a inversões no sentido da deriva litorânea. As setas indicam o sentido da deriva litorânea (segundo Dominguez et al. 1992) (veja Figs. le 2, para localização da planície costeira)

Figure 5 - Doce River strandplain. A. Palaeogeographic maps of the Doce strandplain from 5.1 to $3.8 \mathrm{Ka}$ (modified from Dominguez 1987). B. Enlargement of the northern part of the Doce strandplain illustrating the origin of truncations of beach-ridge sets. These truncations result from inversions in the longshore drift direction. Dashed lines indicate orientation of the shoreline during periods of progradation. Dotted lines indicate orientation of the shoreline during periods of erosion associated with reversals in the longshore drift direction. Arrows denote direction of the longshore drift 


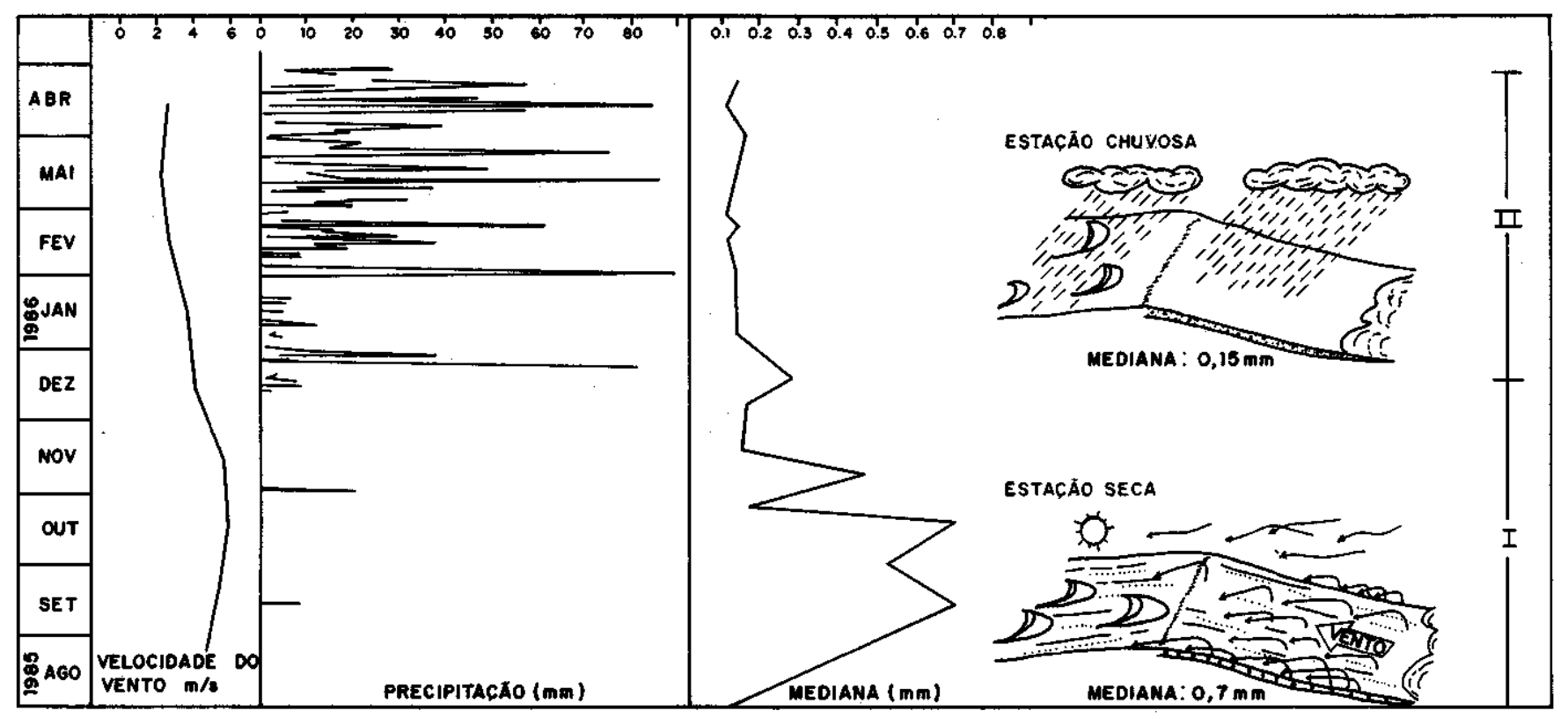

Figura 6-Relações observadas entre precipitação atmosférica e a mediana das areias da face da praia na Praia de Atalaia (PI). Também representadas estão a velocidade dos ventos e um modelo conceituai ilustrando o controle que a precipitação exerce na remoção seletiva pelo vento dafraçãofina das areias da face da praia (veja texto para detalhes) (modificado de Bittencourt et al. 1990)

Figure 6- Observed relationships between rainfall and median of beach-face sands at the Atalaia beach. Also depicted are wind speeds and a conceptual model illustrating the control that rainfall exerts on the selective removal by the wind of the fine-grained beach-face sands (see text for details) (modified from Bittencourt et al. 1990)

que podem ser facilmente identificadas em fotografias aéreas, representam períodos de interrupção da migração das dunas. Feicões similares a essas foram registradas por Purvis (1991), em áreas interdunares no sul da Tunísia.

Campos de dunas costeiras na região Nordeste do Brasil Alguns especialistas, como Goldsmith (1978), têm a opinião de que o clima não é um critério para a acumulação de depositos eólicos ao longo da costa, exceto ao longo de regiões tropicais úmidas. Esta crença é baseada na suposição de que o resfriamento entre a terra e o mar assegura a existência de ventos soprando continente adentro, pelo menos durante algum tempo, independente do padrão geral de circulação dos ventos. Neste trabalho, discorda-se totalmente dessa visão, pelo fato de que, ao longo da costa leste - nordeste do Brasil, o desenvolvimento dos campos de dunas é climaticamente controlado. Ao longo desse trecho, dunas ativas estão presentes apenas naqueles setores onde ocorrem pelo menos quatro meses de seca consecutivos durante o ano (Fig. 7), representados pelas regiões costeiras associadas à desembocadura do Rio São Francisco e ao litoral norte - nordeste (Fig. 7). Deve-se ressaltar que os persistentes ventos alísios soprando continente adentro também constituem importante fator secundário a favorecer o desenvolvimento de dunas ao longo das costas norte e nordeste do Brasil. O mapeamento de algumas dessas áreas tem, adicionalmente, mostrado que, durante o Quaternário, o desenvolvimento dessas dunas tem sido episódico, sugerindo que o clima tem mudado (Bittencourt et al. 1982, Barbosa et al 1992).

Pelo fato de a fonte de sedimentos para o campo de dunas ser a face da praia, qualquer fenómeno que afete a remoção de sedimentos da face da praia afetará também o desenvolvimento do campo de dunas. Como foi demonstrado acima, para a região costeira nordeste do Brasil, o supri-

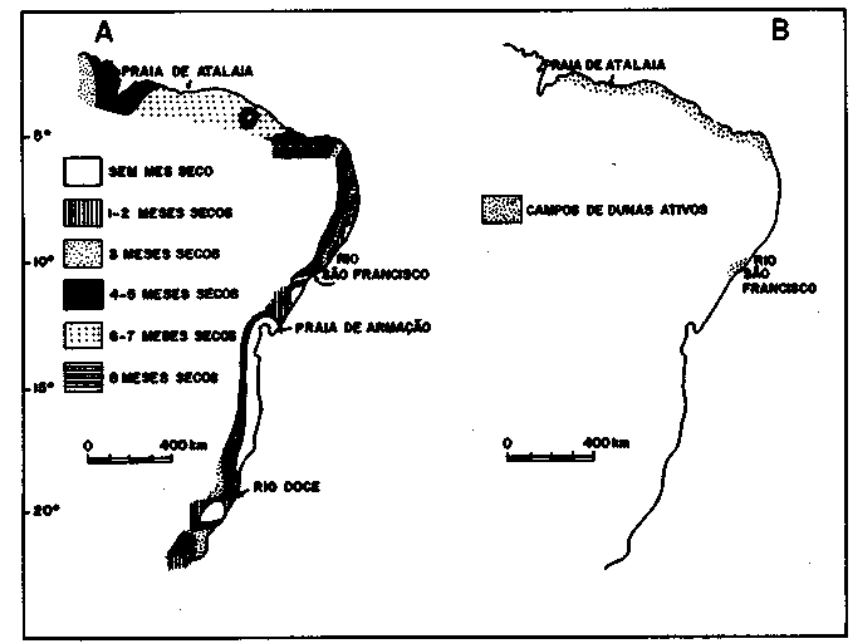

Figura $7-A$. Distribuição do número de meses consecutivos de seca ao longo da costa leste-nordeste do Brasil. $\boldsymbol{B}$. Campos de dunas ativas ao longo da costa leste-nordeste do Brasil (modificado de Dominguez et al. 1992) Figure 7 - East-northeastern coast of Brazil. A. Number of consecutive dry months. B. Active dune fields (modified from Dominguez et al. 1992)

mento de sedimentos para o campo de dunas e a migração das mesmas ocorre predominantemente durante a estação seca, sendo interrompido durante a estação chuvosa. Dessa forma, qualquer mudança climática que impeça o movimento para sul da ZCIT, durante o verão-outono, resultará num decréscimo da precipitação, aumentando o suprimento de sedimentos para o campo de dunas e favorecendo a migração das mesmas. Inversamente, se a ZCIT não se 


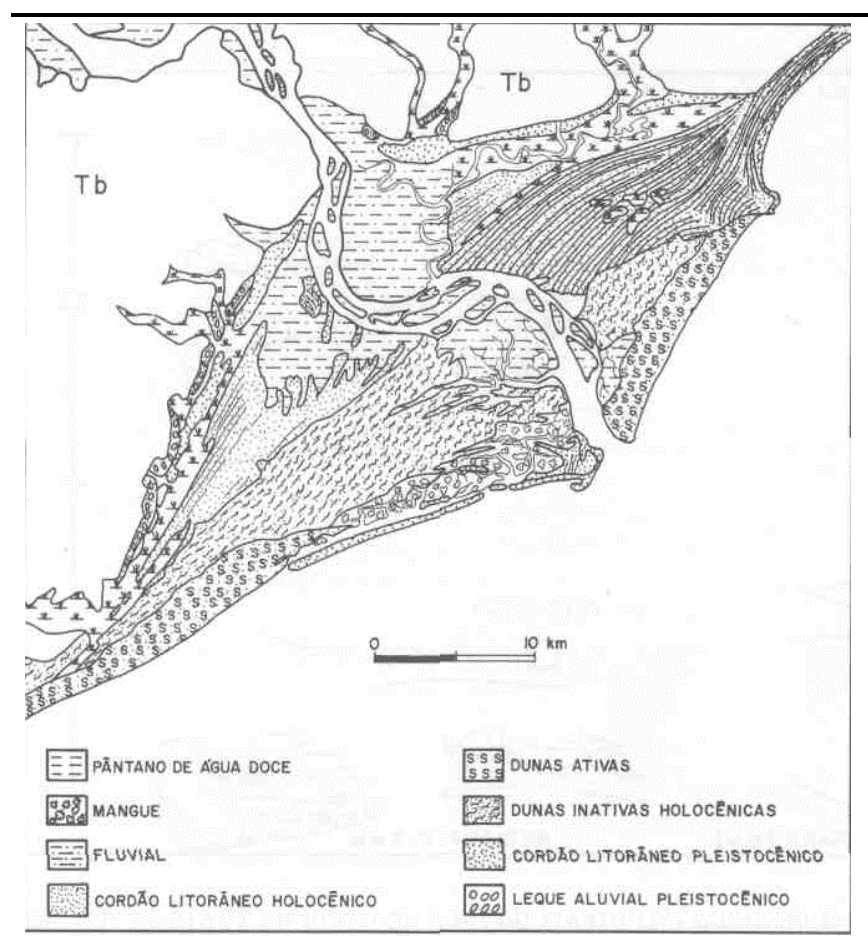

Figura 8 - Mapa geotnórfico dos depósitos quaternários ocorrentes na planície costeira associada à desembocadura do Rio São Francisco, mostrando a existência de duas gerações de dunas de idades holocênicas. A estabilização do campo de dunas antigo está possivelmente relacionado a mudanças climáticas que afetaram essa região (segundo Bittencourt et al. 1982). Ver figura 1, para a localização deste mapa

Figure 8- Geomorphic map of the Quaternary deposits occurring at the São Francisco strandplain, showing the existence of two generations of dune fields of Holocene age. Stabilization of the older dune field is possibly related to climate change affecting this part of the coast (after Bittencourt et al. 1982). See figure 1 for location of the map

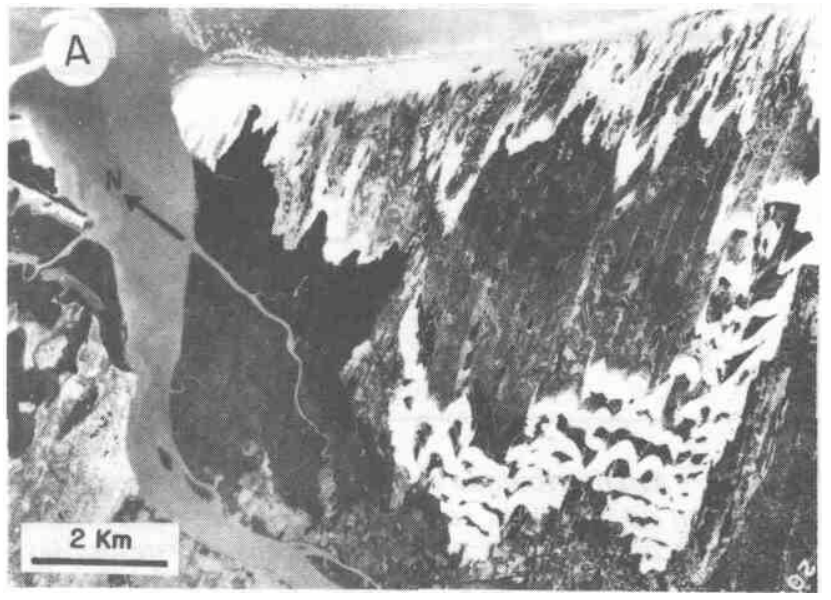

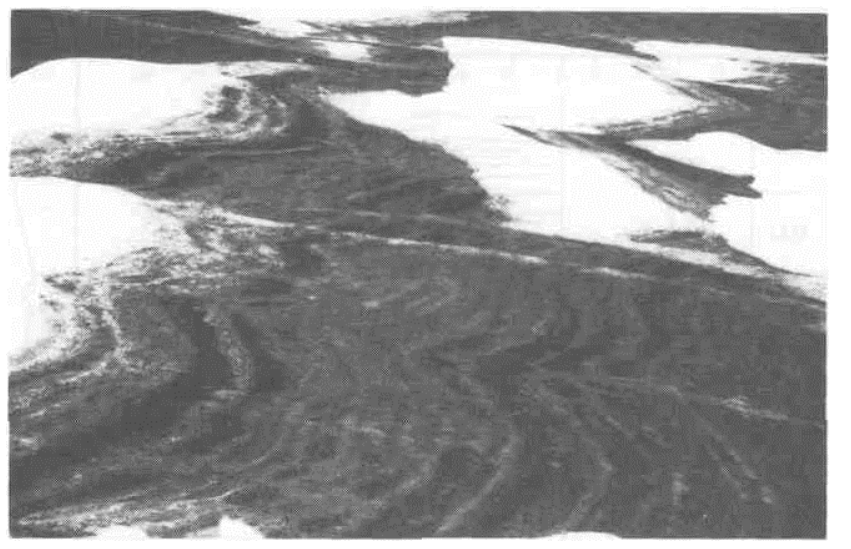

Prancha 1 - Aspecto dos campos de dunas ativas, localizados na costa norte-nordeste do Brasil. As áreas interdunares são caracterizadas por pequenas cristas arqueadas, indicando as posições pretéritas ocupadas pelas dunas. Essas cristas são formadas quando a área interdunar é alagada durante a estação chuvosa, dessa maneira indicando as interrupções na migração das dunas Plate 1 - Aspects of active dune fields on the north-northeastern coast of Brazil. Interdune áreas are characterized by low arcuate ridges indicating former positions occupied by the dunes. These ridges form when the interdune área is flooded during the rainy season, thus indicating interruptions in dune migration

mover para norte durante o inverno-primavera, a duração da estação chuvosa irá aumentar e o suprimento de sedimento para o campo de dunas e a própria migração das mesmas serão interrompidos.

A inspeção de fotografias aéreas da planície costeira, nas vizinhanças da Praia de Atalaia, mostra que o suprimento de sedimentos para o campo de dunas - durante os tempos recentes - não foi um processo contínuo, tendo ocorrido na

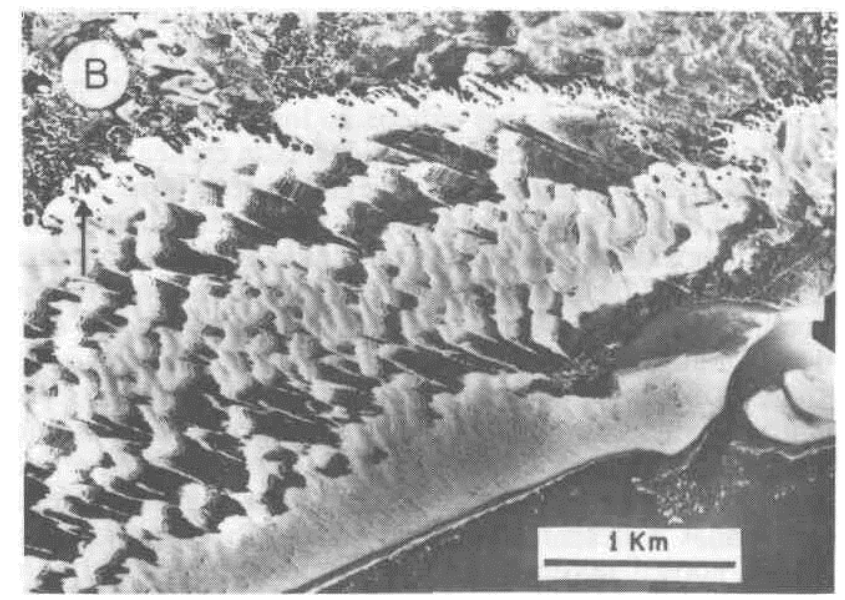

Prancha 2 - Fotografias aéreas verticais ao longo da cosia norte-nordeste do Brasil. A. Campo de dunas nas vizinhanças da Praia de Atalaia (PI) ilustrando o suprimento descontínuo de sedimentos. Este suprimento intermitente pode estar relacionado a variações da ordem de décadas na pluviosidade, associados ao comportamento da Zona de Convergência Intertropical. B. Fotografia ilustrando um suprimento de sedimentos contínuo para o campo de dunas localizado na planície costeira associada à desembocadura do Rio São Francisco. Notar que não existe nenhuma de s continuidade entre a praia e o próprio campo de dunas. A área interior é um antigo campo de dunas de idade holocênica, já estabilizado pela vegetação e, assim, ilustrando o caráter episódico do desenvolvimento das dunas na região, possivelmente relacionado com mudanças climáticas Plate 2 - Vertical aerial photos of active dune fields along the north-northeastern coast of Brazil. A. Dune field occuring in the vicinity of the Atalaia beach (PI) illustrating discontinuous sediment supply. This intermittent supply may be related to decade-long changes in rainfall possibly associated with the behaviour of the ITCZ. B. Photo illustrating continuous sediment supply to the dune field located at São Francisco strandplain. Note that there is no gap between the beach and the dune field itself. Interior área is an old dune field of Holocene age already stabilized by vegetation and thus illustrating the episodic character of dune development in the São Francisco strandplain, possibly related to recent climate changes 
forma de pulsos alternados com períodos durante os quais o suprimento de sedimentos foi consideravelmente reduzido (Prancha 2A). Assumindo que as taxas de transporte na praia e a distribuição granulométrica do sedimento tenham permanecido constantes durante o período, a melhor explicação para esse suprimento intermitente está relacionada a mudanças na precipitação atmosférica ligadas à posição da ZCIT, atuando na escala de tempo de várias décadas. Adicionalmente, Fortes (1992), estudando detalhadamente as cristas arqueadas mencionadas anteriormente, notou que o espaçamento entre elas é variável, mostrando clara correspondência com os ciclos de manchas solares. Esse autor atribui ao fenómeno variações na duração e intensidade da precipitação atmosférica que controlam individualmente, em termos anuais, as taxas de migração das dunas.

Para a planície costeira associada à desembocadura do Rio São Francisco, qualquer mudança climática que resulte em decréscimo na duração da estação seca terá efeitos similares. O mapeamento dessa região (Bittencourt et al. 1982) mostrou a existência de um campo de dunas inativo de idade holocênica, localizado mais para o interior de um campo de dunas ativo, que o está transgredindo (Prancha 2B e Fig. 8). Este campo de dunas inativo possivelmente representa testemunho de uma mudança climática que afetou a área durante o Holoceno. Adicionalmente, Barbosa \& Dominguez (1992) apontam, baseados no mapeamento dos tipos de dunas inativas (predominantemente parabólicas) e ativas (predominantemente barcanas), para um progressivo aumento na aridez do clima, para a região, nos últimos 5.000 anos

CONCLUSÃO

O conhecimento disponível sobre a maneira pela qual o sistema climático funciona, na sua maioria está fundamentado em observações do clima atual. A utilização desse conhecimento para análises prospectivas de climas futuros só terá sentido se o mesmo puder ser calibrado sob uma ampla gama de condições. Infelizmente, tal conhecimento, do ponto de vista de medidas efetuadas pelo homem, está restrito apenas a registros realizados nos últimos dois séculos. Todavia, no caso do hemisfério sul, embora praticamente inexistam registros climáticos históricos (que seriam de grande utilidade para aquele propósito), há a possibilidade de ser utilizada, para reconstruções paleoclimáticas, uma outra fonte disponível, que constitui os chamados dados paleoclimáticos naturais (proxies).

Estudos recentes do Sistema Quaternário Costeiro do Brasil sugerem ser exequível, para as suas costas leste e nordeste, a utilização de padrões de sedimentação costeira como indicadores naturais para reconstruções paleoclimáticas. Dois tipos de padrões de sedimentação se revelaram apropriados para tal fim: (1) padrões associados ao transporte de sedimentos arenosos ao longo da costa por correntes de deriva litorânea, geradas por ondas e controladas climaticamente pelo sistema de ventos dominante e (2) padrões de sedimentação em campos de dunas costeiras, controlados climaticamente por taxas de precipitação e padrões de vento. No primeiro caso, a partir de testemunhos registrados na planície costeira associada à desembocadura do Rio Doce, onde o sentido dominante da deriva litorânea, durante o Holoceno, tem sido de Sul para Norte, foram identificadas importantes inversões no sentido da mesma. Tais inversões devem estar relacionadas fundamentalmente a mudanças no padrão da circulação atmosférica, que teriam impedido os ventos alísios de E-SE de alcançarem essa região, mediante deslocamentos na posição da célula de alta pressão do Atlântico Sul. Nessas circunstâncias, os ventos alísios de E$\mathrm{NE}$ prevaleciam, induzindo uma deriva inversa de Norte para Sul. No segundo caso, concluiu-se que, diferente do que consideram alguns especialistas, o clima é um fator importante para a acumulação de depósitos eólicos ao longo da costa, o que pôde ser demonstrado para os campo de dunas ao longo da região costeira norte-nordeste do Brasil, cujo desenvolvimento é controlado climaticamente. Assim, esses campos de dunas só se desenvolvem em regiões que apresentam pelo menos quatro meses secos consecutivos por ano, bem como ventos alísios que sopram persistentemente continente adentro. Nesse sentido, foi demonstrado que o clima, através da precipitação atmosférica, controla não-somente o suprimento de sedimentos para o campo de dunas ativas, como também a migração das mesmas, que ocorre durante a estação seca, sendo interrompida durante a estação chuvosa. O mapeamento de algumas áreas (planícies costeiras associadas à desembocadura do Rio São Francisco/ $\mathrm{AL}$ e à Praia de Atalaia/PI) mostrou que, durante o Quaternário, o desenvolvimento dessas dunas tem sido episódico, sugerindo que o clima tem mudado. Na Praia de Atalaia, ficou evidenciado que o suprimento de sedimentos para o campo de dunas durante os tempos recentes não foi um processo contínuo, tendo ocorrido na forma de pulsos, alternados com períodos durante os quais o suprimento foi consideravelmente reduzido, o que sugere estar este fato relacionado a mudanças na precipitação atmosférica, ligadas à posição da Zona de Convergência Intertropical (ZCIT), atuando na escala de várias décadas. Dessa maneira, variações climáticas que impeçam o deslocamento para sul da ZCIT, durante o verão - outono, resultarão em significativo decréscimo da precipitação sobre a área, aumentando, portanto, o transporte de sedimentos da face da praia para o campo de dunas. Este fato redundará numa expansão do campo de dunas. Contrariamente, se a ZCIT não se mover para norte durante o inverno - primavera, a duração da estação chuvosa irá aumentar e o suprimento de sedimentos para o campo de dunas e a própria migração das mesmas serão interrompidos.

Concluindo, mostrou-se que a discussão aqui realizada demonstra a praticabilidade de se utilizar os padrões de sedimentação costeira acima analisados como indicadores paleoclimáticos naturais (proxies), restando o desenvolvimento de estudos outros mais aprofundados para avaliar e testar as hipóteses aqui levantadas.

\section{REFERÊNCIAS BIBLIOGRÁFICAS}

AB'SABER, A.N. 1977. Espaços ocupados pela expansão dos climas secos na América do Sul, por ocasião dos períodos glaciais quaternários. Paleoclimas, 3:1-20.

ABSY, M.L.; SERVANT, M.; ABSY, M.L. 1993. A história do clima e da vegetacão pelo estudo do pólen. Ciência Hoje, 16:26-30.

BARBOSA, L.M. \& DOMINGUEZ, J.M.L. 1992. Dunas costeiras associadas à desembocadura do Rio São Francisco: morfologia e implicacões paleoclimáticas. In: CONGR. BRÁS. GEOL., 37. São Paulo, 1992. Boletim de Resumos Expandidos... São Paulo, SBG. v. 1, p. 101-102.

BIGARELLA, J.J. 1972. Eolian environments: their characteristics, recognition and importance. In: RIGBY, J.K. \& HAMBLIN, W.K. eds. Recognition of Ancient Sedimentary Environments. Oklahoma, Soe. Econ. Paleont. Mineral, p. 12-62. (Special Publ. 16).
BITTENCOURT, A.C.S.P.; DOMINGUEZ, J.M.L.; MOITA FILHO, O. 1990. Variações texturais induzidas pelo vento nos sedimentos da face da praia (Praia de Atalaia-Piauí). Rev. Brás. Geoc., 20:201-207.

BITTENCOURT, A.C.S.P. FARIAS, F.F; ZANINI, A. 1987. Reflexo das variações morfodinâmicas praiais nas características texturais dos sedimentos da praia de Armação, Salvador, Bahia. Rev. Brás. Geoc., 17:276-282.

BITTENCOURT, A.C.S.P.; DOMINGUEZ, J.M.L.; MARTIN, L; FERREIRA, Y.A. 1982. Dados preliminares sobre a evolução do delta do Rio São Francisco (SE/AL) durante o Quaternário: influência das variações do nível do mar. In: SIMP. QUATERNÁRIO NO BRASIL, 4. Rio de Janeiro, 1981. Anais... São Paulo, SBG. p. 49-68.

BRADLEY, R.S. 1985. Quaternary Paleoclimatology: Methods of Paleoclimatic Reconstruction. Boston, Allen \& Unwin. 472 p. 
BRYSON, R.A. \& MURRAY, T.J. 1977. Climates ofHunger - Mankind and the World's Changing Weather. Wisconsin, The University of Wisconsin Press. $171 \mathrm{p}$.

CURRAY, J.R.; EMMEL, F.J.; CRAMPTON, P.J.S. 1967. Holocene history of a strandplain, lagoonal coast, Nayarit, México. In: CASTENARES, A.A. \& PHELGER, RB. eds. Lagunas Costeras, Un Simpósio. México, Univ. Nac. Auton. México, p. 63-100.

DAVIES, J.L. 1972. Geographical Variation in Coastal Development. New York, Longman. $204 \mathrm{p}$

DOMINGUEZ, J.M.L. 1987. Quaternary Sea-Level Changes and the Depositional Architecture of Beach-Ridge Strandplains Along the Coast of Brazil. USA. 288 p. (PhD Dissertation, University of Miami).

DOMINGUEZ, J.M.L. \& WANLESS, H.R. 1991. Fácies arquitecture of a falling sea levei strandplain, Doce river coast, Brazil. In: SWIFT, D.J.P. \& OERTEL, G.F. eds. Shelf Sandstone Bodies. Oklahoma, Int. Assoe. Sed. p. 259-286. (Special Publ. 14).

DOMINGUEZ, J.M.L.; BITTENCOURT, A.C.S.P.; MARTIN, L. 1983. $\mathrm{O}$ papel da deriva litorânea de sedimentos arenosos na construção das planícies costeiras associadas às desembocaduras dos Rios São Francisco (SE/AL), Jequitinhonha (BA) e Paraíba do Sul (RJ). Rev. Brás. Geoc., 13:98-105.

DOMINGUEZ, J.M.L.; BITTENCOURT, A.C.S.P.; MARTIN, L. 1987. Sealevel history and quaternary evolution of river-mouth-associated beach-ridge plains along the eastern/southeastern brazilian coast: a summary. In: NUMMEDAL, D.; PILKEY, O.H.; HOWARD, J.D. eds. Sealevel Fluctuation and Coastal Evolution. Oxford, Soe. Econ. Paleont. Mineral, v. 41, p. 115-127.

DOMINGUEZ, J.M.L.; BITTENCOURT, A.C.S.P.; MARTIN, L. 1992. Controls on Quaternary coastal evolution of the east-northeastern coast of Brazil: roles of sea-level history, trade winds and climate. Sediment. Geol, 80:213-232.

FARIAS, F.F.; BITTENCOURT, A.C.S.P.; ZANINI, A., Jr.; DOMINGUEZ, J.M.L. 1985. Variações temporais e espaciais na dinâmica de sedimentação da Praia de Armação - Salvador, Bahia. Rev. Brás. Geoc., 15:48-54.

FORTES, F.P. 1992. As manchas solares e o passo das dunas. In: CONGR. BRÂS. GEOL., 37. São Paulo, 1992. Boletim de Resumos Expandidos... São Paulo, SBG. v. 2, p. 297-298.
GOLDSMITH, V. 1978. Coastal dunes. In: DAVIES, R.A., Jr. ed. Coastal Sedimentary Environments. New York, Springer-Verlag. p. 171-236.

GRIBBIN, J. \& LAMB, H.H. 1978. Climatic change in historical times. In: GRIBBIN, J. ed. Climatic Change. Cambridge, Cambridge University Press. p. 68-82.

HASTENRATH S. \& LAMB, RJ. 1977. Climatic Atlas of the Tropical Atlantic and Eastern Pacific Oceans. Wisconsin, The University of Wisconsin Press, (sem numeração sequencial).

KOMAR, P.D. 1976. Beach Processes and Sedimentation. Englewood Cliffs, Prentice-Hall. 429 p.

LINS, R.C. 1978. Bacia do Parnaiba: Aspectos Fisiográficos. Recife, Inst. Joaquim Nabuco de Pesquisas Sociais. 65 p.

MARTIN, L. \& SUGUIO, K. 1992. Variation of coastal dynamics during the last 7,000 years recorded in beach-ridge plains associated with river mouths: example from the central brazilian coast. Palaeogeogr. Palaeoclimatol. Palaeoecol, 99:119-140.

NIMER, E. 1989. Climatologia do Brasil. Rio de Janeiro, IBGE. 421 p.

PURVIS, K. 1991. Stoss-side mud-drapes: deposits of interdune pond margins. Sedimentology, 38:153-156.

SHEPARD, F.P. 1950. Longshore Bars and Longshore Troughs. USA U.S. Army Corps of Eng. p. 121-156. (Tech. Mem. 15, Beach Erosion Board).

SWIFT, D.J.P. 1975. Barrier island evolution génesis: evidence from the Central Atlantic shelf, Eastern USA. Sediment. Geol., 14: 1-43.

TURCO, B.; SUGUIO, K.; MARTIN, L.; FLEXOR, J-M. 1993. Registros milenares nos sedimentos dos lagos da Serra de Carajás. Ciência Hoje, 16:31-35.

US-GARP. 1975. Understanding Climatic Change, aProgramfor Action. United States Commitee for the Global Atmospheric Research Program. Washington D.C., National Academy of Sciences. 239 p.

WRIGHT, L.D. \& SHORT, A.D. 1982. Morphodynamic variability of surf zones andbeaches: a synthesis.Mar. Geol., 56:93-118.

MANUSCRITO A809

Recebido em 14 de dezembro de 1993 Revisão do autor em 2 de agosto de 1994 Revisão aceita em 17 de agosto de 1994 